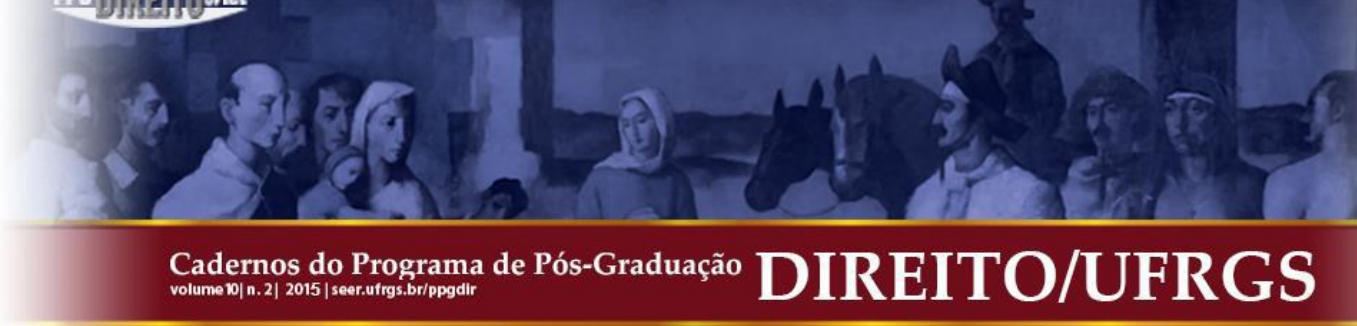

\title{
DIREITO AO AMBIENTE E INFORMAÇÃO: A PERCEPÇÃO DO CIDADÃO ACERCA DA RESPONSABILIDADE NA DESTINAÇÃO DOS RESÍDUOS DOMÉSTICOS *
}

\author{
ENVIRONMENTAL LAW AND INFORMATION: CITIZEN'S PERCEPTION REGARDING \\ HOUSEHOLD WASTE DESTINATION
}

\author{
Ana Christina Konrad** \\ Jane Márcia Mazzarino**** \\ Luciana Turatti*****
}

\begin{abstract}
RESUMO: Este artigo tem como objetivo analisar as representações dos cidadãos sobre a responsabilidade na destinação dos resíduos sólidos domésticos, e, por consequência, refletir sobre os aspectos éticos pertinentes à questão. Para o aprofundamento da discussão realizou-se uma pesquisa de cunho exploratório e descritivo, com uma abordagem qualitativa, no município de Lajeado, Vale do Taquari, RS, Brasil. A população e amostra do estudo é composta por 120 cidadãos de faixa etária e escolaridade diversas, moradores de diferentes bairros da cidade. Foram utilizadas entrevistas semi-estruturadas para a coleta de informações. Concluiu-se que a tendência dos moradores é transferir a responsabilidade para com os resíduos para o poder público. Os moradores não percebem uma preocupação coletiva com a questão dos resíduos na comunidade em que vivem, o que reflete as posturas individuais dos entrevistados.
\end{abstract}

PALAVRAS-CHAVE: Direito ambiental. Informação. Responsabilização. Coleta seletiva. Análise de conteúdo.
ABSTRACT: The purpose of this article is to analyze citizens' representations on the responsibility for domestic solid waste destination, and consequently, to reflect upon the ethical questions concerning this issue. In order to deepen the discussion an exploratory and descriptive research has been carried out, with a qualitative approach, in the municipality of Lajeado, Taquari Valley, RS, Brazil. The study sample contains 120 citizens with various ages and education levels, residents in different city boroughs. Semi-structured interviews have been used so as to collect information. It has been concluded that the residents tend to transfer the responsibility for the waste to the public power. They do not perceive a collective concern regarding the waste issue in the community they live in, which reflects the interviewees' individual opinions.

KEYWORDS: Environmental law. Information. Responsibility. Sorted waste collection. Content analysis.

SUMÁRIO: Introdução. 1. Linhas de pensamento acerca do tema. 1.1. O direito ao meio ambiente como direito fundamental. 1.2. O direito à informação e à responsabilidade (dever) ambiental. 1.3. Ética e cidadania ambiental. 2. Método. 2.1. Ambiente da pesquisa e universo amostral. 2.2. Tratamento dos dados. 3. Apresentação dos resultados da pesquisa. 4. Discussão dos Resultados. Considerações finais. Referências.

\section{INTRODUÇÃO}

As atuais discussões em torno da correta destinação dos resíduos sólidos domésticos atingem não só as comunidades locais, mas em especial a comunidade global, pela existência

\footnotetext{
* Este estudo é resultado de pesquisa apoiada pela Fundação de Amparo à Pesquisa do Estado do Rio Grande do Sul - FAPERGS.

** Bacharel em Direito pela UNIVATES, Lajeado, RS.

**** Professora do Curso de Comunicação e do Programa de Pós Graduação em Ambiente e Desenvolvimento do Centro Universitário UNIVATES, Lajeado, RS. Doutora em Comunicação.

***** Professora do Curso de Direito e Engenharia Ambiental e do Programa de Pós Graduação em Ambiente e Desenvolvimento do Centro Universitário UNIVATES, Lajeado, RS. Doutora em Direito.
} 


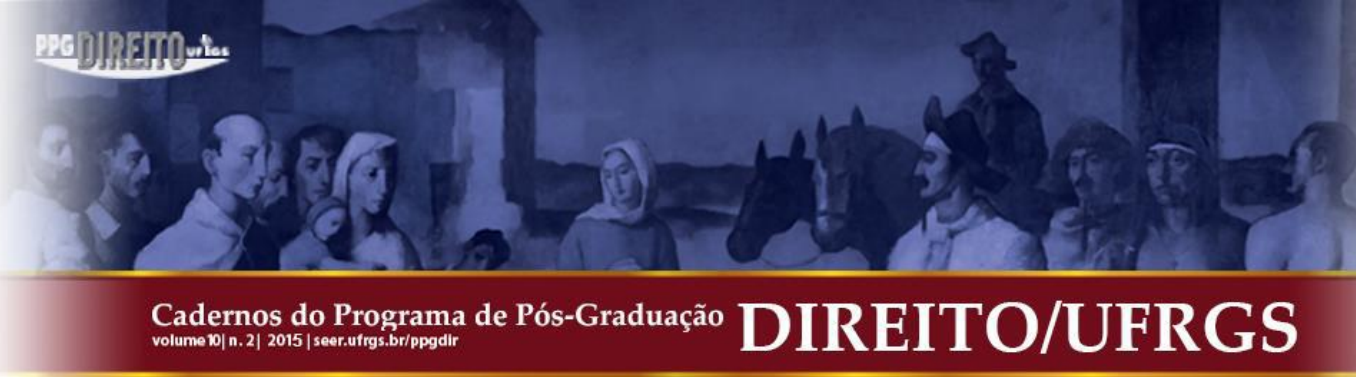

de um panorama no qual a produção de resíduos é crescente, assim como as limitações técnicas e geográficas dos aterros sanitários.

Historicamente se experimenta um avanço tecnológico sem precedentes, aliado a um irresistível apelo ao consumo. Paralelamente, emerge o que se convencionou denominar de risco ambiental. Neste cenário, o papel do cidadão necessita transcender sua tradicional formatação e passa a abrigar as questões ambientais. Portanto, problematiza-se: como os cidadãos representam sua responsabilidade em relação à questão ambiental, especificamente no que tange aos resíduos domésticos? O problema ampara-se em alguns questionamentos: qual é a responsabilidade do cidadão em relação a destinação dos resíduos que produz no seu cotidiano? Em que sentido a legislação avança em relação às responsabilidades individuais? Como se relacionam os aspectos éticos com a atitude final do descarte de resíduos?

O objetivo do estudo é analisar as representações dos cidadãos sobre a sua responsabilidade na destinação dos resíduos domésticos e relacionar suas falas com os pressupostos legais existentes, além de discutir os aspectos éticos implicados para, por fim,

apresentar algumas proposições com o objetivo de se aperfeiçoarem as políticas públicas de informação para coleta seletiva de resíduos sólidos domésticos.

Para se alcançar tal propósito, num primeiro momento, foram analisadas as linhas de pensamento que permeiam a discussão central do presente artigo, quais sejam: o entendimento de que o meio ambiente é um direito fundamental; o direito à informação e a consequente responsabilidade dos cidadãos para com o meio ambiente; a ética e a cidadania ambiental. Posteriormente, foi descrita a metodologia empregada no desenvolvimento do estudo, que considerou como área de abrangência o município de Lajeado/RS. Em seguida são apresentados os resultados da pesquisa e, na sequência, os mesmos são discutidos com base nas linhas de pensamento apresentadas.

\section{LINHAS DE PENSAMENTO ACERCA DO TEMA}

Para compor a análise da temática central deste artigo, são desenvolvidas três linhas de pensamento teórico: o direito ao meio ambiente como direito fundamental; o direito à informação e a responsabilidade (dever) ambiental; e ética e cidadania ambiental. No capítulo seguinte este referencial será relacionado com os resultados do estudo empírico. 


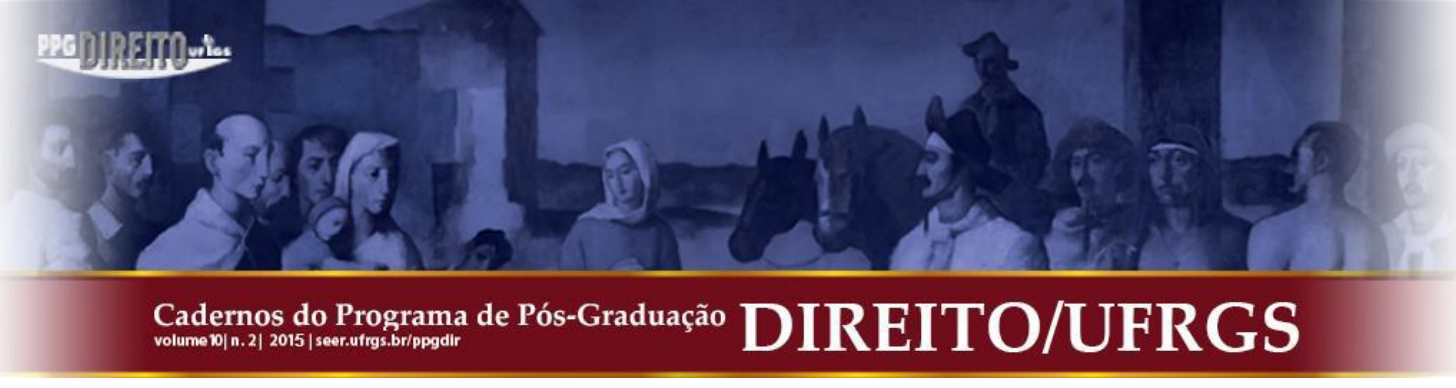

humanismo e universalidade, os direitos de terceira geração tendem a cristalizar-se neste fim de século enquanto direitos que não se destinam especificamente à proteção dos interesses de um indivíduo, de um grupo ou de um determinado Estado. Tem primeiro por destinatário o gênero humano mesmo, num momento expressivo de sua afirmação como valor supremo em termo de existencialidade concreta. Os publicistas e juristas já os enumeram com familiaridade, assinalandolhe o caráter fascinante de coroamento de uma evolução de trezentos anos na esteira da concretização dos direitos fundamentais. Emergiram eles da reflexão sobre temas referentes ao desenvolvimento, à paz, ao meio ambiente, à comunicação e ao patrimônio comum da humanidade (BONAVIDES, 2002, p. 523).

O autor destaca que o destinatário dos direitos de terceira geração é o gênero humano em sua existência concreta. Neste sentido, Leite e Canotilho (2007, p. 103) complementam afirmando que o direito ao meio ambiente ecologicamente equilibrado está alicerçado na "fraternidade" ou na "solidariedade".

Daí a associação direta entre o direito ao meio ambiente ecologicamente equilibrado e o direito à vida - motivo que reforça seu caráter de fundamental - posição compartilhada por Milaré:

[...] o reconhecimento do direito a um meio ambiente sadio configura-se, na verdade, como extensão do direito à vida, quer sob o enfoque da própria existência física e saúde dos seres humanos, quer quanto ao aspecto da dignidade desta existência - a qualidade de vida -, que faz com que valha a pena viver. Deveras, o caráter fundamental do direito à vida torna inadequados enfoques restritos do mesmo em nossos dias; sob o direito à vida, em seu sentido próprio e moderno, não só se mantém a proteção contra qualquer privação arbitrária da vida, mas além disso encontram-se os Estados no dever de buscar diretrizes destinadas a assegurar o acesso aos meios de sobrevivência a todos os indivíduos e todos os povos. Neste propósito, têm os Estados a obrigação de evitar riscos ambientais sérios à vida (MILARÈ, 2000, p. 96).

Fica evidente assim que o direito a um meio ambiente sadio e ecologicamente equilibrado relaciona-se à qualidade de vida, e que cabe ao Estado assegurá-lo por se tratar de uma extensão do direito à vida.

\section{$1.2 \mathrm{O}$ direito à informação e à responsabilidade (dever) ambiental}

O direito à informação encontra respaldo na Carta Magna de 1988, que assegura, em seu artigo $5^{\circ}$, incisos XIV e XXXIII, a todos o acesso à informação. Também dispõe que: 


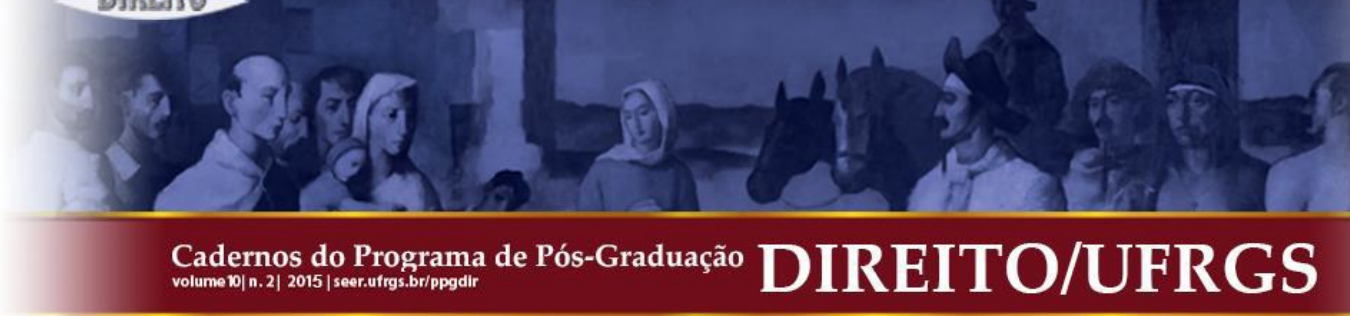

[...] todos têm direito a receber dos órgãos públicos informação de seu interesse particular, ou de interesse coletivo ou geral, que são prestados no prazo da lei, sob pena de responsabilidade, ressalvadas aquelas cujo sigilo seja imprescindível à segurança da sociedade e do Estado" (BRASIL, 1988).

A Política Nacional do Meio Ambiente (PNMA), Lei $n^{\circ}$ 6.938/81, faz referência a este direito em seu artigo $4^{\circ}$, inciso $\mathrm{V}$, quando estabelece que "a PNMA visará: à divulgação de dados e informações ambientais e à formação de uma consciência pública sobre a necessidade de preservação da qualidade ambiental e do equilíbrio ecológico". O artigo $9^{\circ}$, inciso VII, prevê como instrumentos da PNMA o sistema nacional de informação sobre o meio ambiente. Legalmente, portanto, cabe ao Estado a criação de mecanismos adequados para garantia de tal direito e ao cidadão a busca da informação junto aos órgãos públicos.

Corroborando com tal disposição, em 18 de novembro de 2011, foi publicada a Lei Federal $\mathrm{n}^{\mathrm{o}} 12.527$ com o objetivo de regular o acesso a informações previsto no inciso XXXIII do art. $5^{\circ}$, no inciso II do $\S 3^{\circ}$ do art. 37 e no $\S 2^{\circ}$ do art. 216 da Constituição Federal, estabelecendo os procedimentos a serem observados pela União, Estados, Distrito Federal e Municípios.

A partir da difusão da correta informação ambiental, o Estado passa a ser ente legítimo para aplicar a responsabilização àqueles que promovem danos ao meio ambiente. No mundo globalizado contemporâneo este processo de informação ambiental amplo só é passível de ser desencadeado utilizando-se os meios de comunicação.

Como defende Gentilli (2012, p. 6) "a informação é uma prerrogativa para que o cidadão tenha plenas condições de fazer suas escolhas. Relaciona-se à liberdade de expressão. É a forma como se manifesta presentemente a liberdade de manifestação e de expressão no contexto do Estado de direito".

Compreendido como um direito, a informação não possui um fim em si mesmo, mas um propósito maior, relacionado a "capacidade de facilitar ao cidadão ao acesso aos demais direitos declarados". (GENTILLI, 2012, p. 6) Numa sociedade que se intitula democrática o alargamento da cidadania por meio do acesso a outros direitos não pode ser mera promessa, também porque é partir deste processo que se faz possível a construção da responsabilidade ambiental.

Oliveira (2005) explica que responsabilidade é uma palavra utilizada para ligar o dever à obrigação, que decorre de contrato verbal do antigo direito romano. Significa que alguém deve responder por seus atos danosos, o que traduz a noção de justiça existente no grupo 


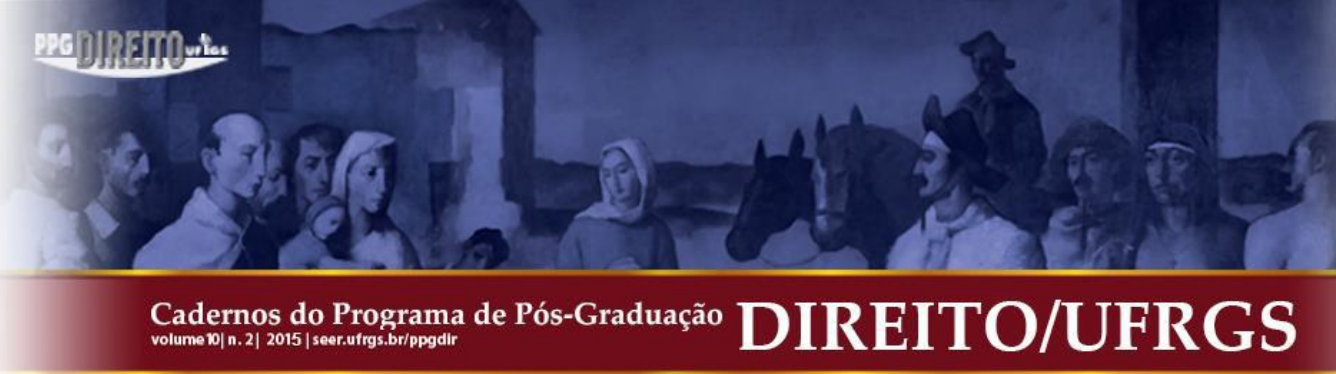

social. Para o sistema jurídico a responsabilização implica no dever moral de não prejudicar outrem, o que requer saber se o prejuízo deve ou não ser reparado por quem o causou, em que condições e quais maneiras poderão ser feitos os reparos.

Contextualizando tal responsabilidade dentro da temática ambiental Ost (1995) defende que a necessidade de proteção da natureza esteja vinculada à existência de alguns direitos, ou seja, o mesmo trabalha com a conotação do binômio direito-dever. Para o autor o critério da responsabilidade estabelece uma importante diferença entre o homem e os demais seres vivos, pois, entre todas as criaturas vivas o homem é o único ser que possui acesso ao sentido. Animais e plantas possuem direitos, mas é o homem que tem deveres a cumprir, que se estendem a toda humanidade, inclusive às futuras gerações. Assim, a tarefa de proteção do meio ambiente se coloca como inerente à espécie humana, podendo aquele que ocasiona o dano ser responsabilizado pelos seus atos, sejam eles decorrentes de suas palavras ou atitudes.

É neste sentido que a Constituição Federal de 1988 estabelece, em seu artigo $225, \S 3^{\circ}$, que "as condutas e atividades consideradas lesivas ao meio ambiente sujeitarão os infratores, pessoas físicas ou jurídicas, a sanções penais e administrativas, independentemente da obrigação de reparar os danos causados" (BRASIL, 1988).

A Política Nacional do Meio Ambiente (PNMA) também fez alusão ao tema, estabelecendo em seu art. $3^{\circ}$, IV, a responsabilidade ambiental. Segundo esta lei o poluidor pessoa física ou jurídica, de direito público ou privado, é responsável direta ou indiretamente pela atividade causadora de degradação ambiental. A PNMA, no art. $4^{\circ}$, VII, impõe ao poluidor e ao predador a obrigação de recuperar ou indenizar os danos causados e, ao usuário, a contribuição pela utilização de recursos ambientais com fins econômicos. Esta lei concedeu ao Ministério Público legitimidade para propor ação penal e civil contra os causadores de dano ambiental.

O descarte indevido de resíduos também pode acarretar a responsabilização do infrator. O Código Estadual do Meio Ambiente do Rio Grande do Sul, instituído pela Lei n ${ }^{\circ}$ 11.520/00, prevê no seu art. 219 que a segregação dos resíduos sólidos domésticos é responsabilidade de toda a sociedade e será gradativamente implantada pelo Estado e pelos municípios, mediante programas educacionais e projetos de reciclagem.

Verifica-se assim que a responsabilidade pelos resíduos sólidos domésticos não pertence apenas ao poder público. A Lei Federal $n^{\circ} 12.305$ de 2010, que institui a Política Nacional de Resíduos Sólidos (PNRS), introduziu um novo conceito de responsabilidade: o 


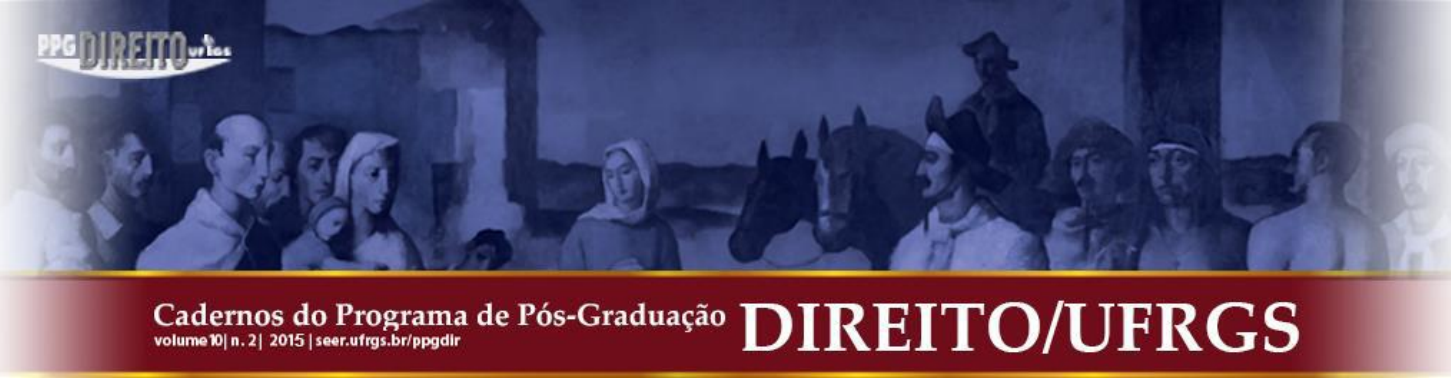

de responsabilidade compartilhada pelo ciclo de vida dos produtos. Tal responsabilidade é definida pela lei como o

[...] conjunto de atribuições individualizadas e encadeadas dos fabricantes, importadores, distribuidores e comerciantes, dos consumidores e dos titulares dos serviços públicos de limpeza urbana e de manejo dos resíduos sólidos, para minimizar o volume de resíduos sólidos e rejeitos gerados, bem como para reduzir os impactos causados à saúde humana e à qualidade ambiental decorrentes do ciclo de vida dos produtos [...]. (BRASIL, 2010)

A lei ultrapassou a relação vendedor-consumidor, empregada nas legislações até então, responsabilizando todos aqueles que se envolvem com o ciclo de vida da produção. As questões da informação e da responsabilidade também foram aprofundadas na nova Política Nacional de Resíduos Sólidos (PNRS), o que está incluso no conceito de controle social e de destinação.

O controle social é definido como o conjunto de procedimentos e mecanismos que garantam informações e participação na formulação, implementação e avaliação das políticas públicas relacionadas aos resíduos sólidos. Já a destinação final ambientalmente adequada, segundo a PNRS, inclui a reutilização, reciclagem, compostagem, recuperação e aproveitamento energético entre outras destinações, inclusive a disposição final, sempre observando normas para evitar riscos ou danos à saúde pública e segurança, visando minimizar os impactos ambientais.

São considerados geradores de resíduos sólidos as pessoas físicas ou jurídicas, de direito público ou privado que geram resíduos sólidos através de suas atividades, incluindo o consumo. Portanto, cabe a todos buscar e obter informação e responsabilizar-se pelos resíduos gerados a partir de suas escolhas de consumo cotidianas.

A PNRS segue como princípios fundamentais a prevenção e precaução, a partir de uma visão sistêmica da gestão dos resíduos sólidos, considerando as variáveis ambiental, social, cultural, econômica, tecnológica e saúde pública, responsabilidade compartilhada pelo ciclo de vida dos produtos, direito da sociedade à informação e controle social, dentre outros.

Esta lei objetiva a não geração, redução, reutilização, reciclagem e tratamento dos resíduos sólidos, bem como disposição ambientalmente adequada. E prevê, como instrumentos, a educação ambiental e a construção de planos de resíduos sólidos (nacional, estaduais, microrregionais, metropolitanos, intermunicipais, municipais) e os planos de gerenciamento. Portanto, além de ser um pressuposto legal, assumir a responsabilidade pela geração dos resíduos também é uma questão ética. 


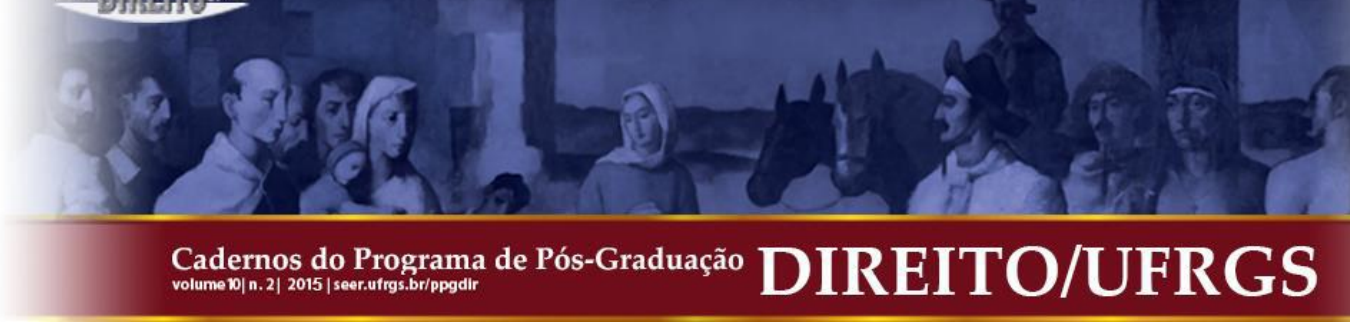

\section{3 Ética e cidadania ambiental}

Segundo Boff (2003) a ética é uma concepção que diz respeito à vida, regulamentando valores e princípios que regem as pessoas e a sociedade. Para Zancanaro (2003) o homem moderno depara-se com a ameaça ao meio ambiente, portanto, refletir sobre ética é uma questão de sobrevivência.

Com a Revolução Científica e o paradigma cartesiano impôs-se à estrutura do saber e à civilização tecno-industrial a ideia do mundo enquanto uma máquina. Com a Revolução Industrial, o rigor cientifico, a noção de progresso e a visão racionalista passaram a ser consideradas motivo de emancipação e felicidade, o que degenerou na razão instrumental, calculista, determinada pelos processos técnicos e utilitaristas de um sistema que, em se tratando de questões ambientais, muitas vezes escapa ao controle humano. A autonomia da razão revelou-se como um processo de conquista do mundo como objeto, o que foi preconizado por Descartes, Galileu Galilei, Bacon entre outros cientistas que contribuíram para um olhar mecanicista e rígido sobre a vida (PELIZZOLI, 2002).

O supremo valor da liberdade, através do bem-estar humano e do progresso proporcionados pela Revolução Industrial e pelo avanço tecnológico, liga-se à política liberal de mercado e ao crescimento capitalista, que seguem impregnando o pensamento atual. Segundo Pelizzoli (2002) para os neoliberais não existia um sistema que oferecesse realização humana maior, pois as chances de liberdade estariam à disposição de todos, asseverados pelo "estado de direito" na democracia, pelo "direito liberal moderno", pelas pessoas e nações "livres e modernas", que obtiveram conquistas com o contrato social.

A ética do mundo neoliberal e liberal surge do principio de que todos os homens procuram a própria felicidade. Como as pessoas possuem capacidades e personalidades diferentes, os que lutam mais obtêm bens e postos melhores. A ética utilitarista vigora em um contexto em que o valor supremo do individuo e de sua liberdade se concretizariam pela produção de consumo e pela propriedade privada de bens, passando a fazer parte da identidade humana, da auto-afimação do sujeito, de uma noção tradicional de família, grupo ou classe (PELIZZOLI, 2002).

A ética neodarwinista pressupõe que a competitividade e a concorrência são necessárias ao aprimoramento, à produtividade e à eficiência, assim aceita-se que o mais forte se adapta melhor e, portanto, possui direito natural sobre tudo que conquistou. Para Pelizzoli 


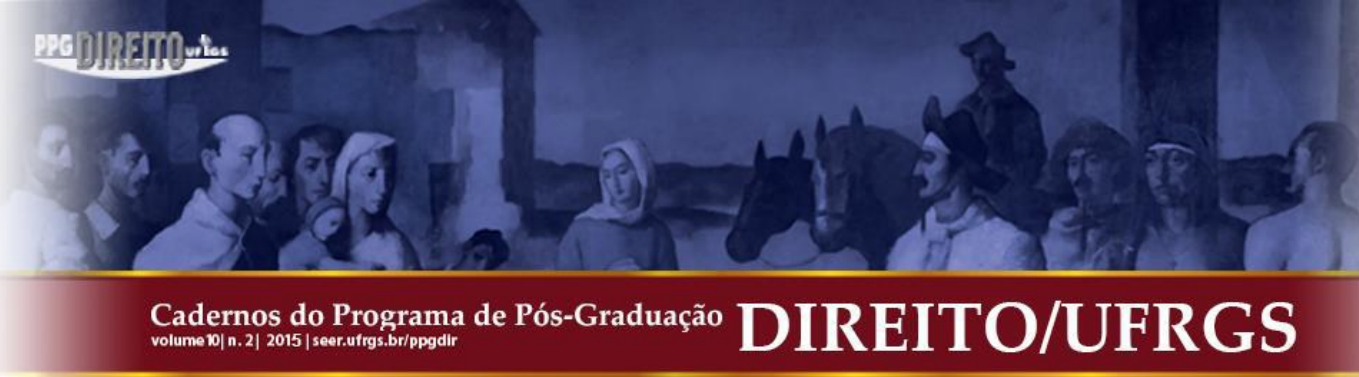

A cidadania ambiental objetiva a proteção intercomunitária do bem dilatado ambiental, debandando dos elementos mencionados na cidadania clássica, a qual, de acordo com Leite e Ayala (2004), é composta por três características elementares, cidadania civil, política e a social, sendo que a cidadania civil está relacionada à liberdade individual, a cidadania política ao direito de exercer o poder político e a cidadania social visa o bem-estar social. Seus fundamentos são a solidariedade e participação responsável na proteção ambiental, para o que cidadão não terá um compromisso de lealdade nacional, mas sim de lealdade ecológica. Deve ser exercida individualmente e coletivamente, priorizando a ação coletiva para obter maior força nas reivindicações de proteção ambiental. Este modelo de cidadania se manifesta se houver uma transformação no jeito de pensar e viver do homem, pois exige uma visão consciente e solidária do cidadão (LEITE e AYALA, 2004).

De acordo com Smith (1998), as atitudes humanas no presente irão determinar quais gerações futuras terão existência. Neste sentido, os impactos de longa duração, como o descarte indevido de lixo, demonstram algumas das dificuldades que as gerações futuras enfrentarão, já que a poluição e a diminuição dos recursos naturais terão efeito sobre as condições das vidas futuras. Reconhecer as obrigações com as gerações futuras é uma questão ética fundamental.

Para o referido autor, as gerações atuais não podem empregar práticas que criem riscos das gerações futuras viverem com dignidade. As gerações atuais necessitam agir de maneira sensível e responsável no sentido de diminuir riscos, já que todas as atitudes de consequências indeterminadas podem atingir seus próprios filhos.

A partir dos pressupostos teóricos analisam-se as representações sociais dos moradores de Lajeado, a fim de discutir aspectos éticos relativos ao direito ao ambiente equilibrado, ao dever de zelar para isto, ao direito à informação, bem como ao dever de informar-se e participar, agindo à luz da cidadania ambiental.

\section{MÉTODO}

Trata-se de uma pesquisa exploratória e descritiva, com abordagem qualitativa, já que visa tanto tornar o problema mais explícito, quanto identificar as características dos fenômenos, de modo a possibilitar uma análise aprofundada. 


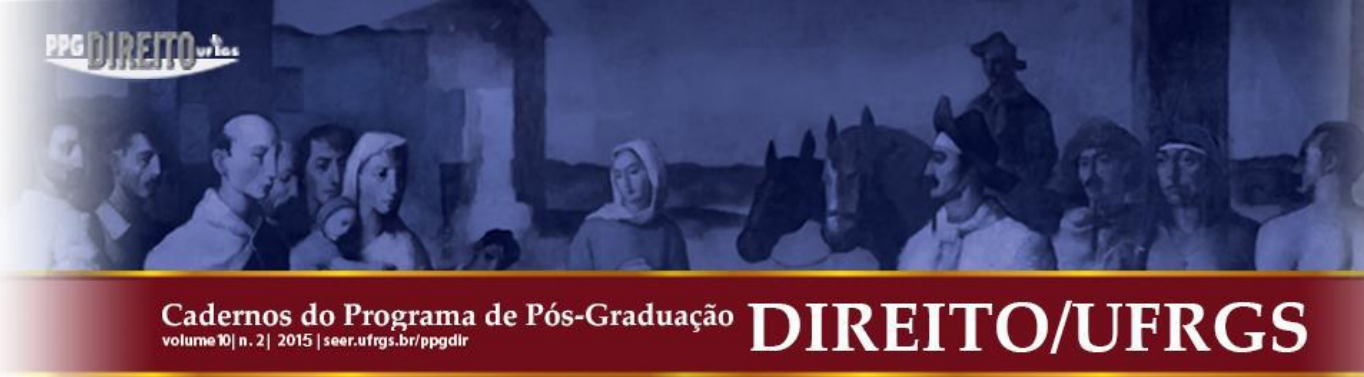

Segundo Brevidelli e De Domenico (2006), neste tipo de pesquisa o pesquisador quer saciar uma inquietação a respeito de uma situação ou fenômeno pouco conhecido, onde ele acaba construindo um cenário, para após explorar os dados e, assim, traçar um perfil dos sujeitos.

Esta opção mostra-se adequada para compreender um fenômeno social, pois possibilita descrever a complexidade do problema, os processos dinâmicos vividos pelos grupos sociais e entender as particularidades do comportamento dos indivíduos em relação à questão dos resíduos e os aspectos legais relacionados.

\subsection{Ambiente da pesquisa e universo amostral}

Quanto à população e amostra, esta é não probabilística, tendo sido escolhida por acessibilidade e tipicidade. A amostra não probabilística caracteriza-se quando os sujeitos são escolhidos por critérios estabelecidos pelos pesquisadores. A acessibilidade caracteriza-se pelo fácil acesso ao público alvo e a tipicidade pela representação que a população alvo deve ter para que se obtenha o conhecimento aprofundado do tema.

Para se analisar as representações sobre a destinação dos resíduos entrevistaram-se 120 cidadãos de faixas etárias diversas, moradores dos 26 bairros da cidade de Lajeado, que aceitaram participar da pesquisa de forma voluntária. As entrevistas foram realizadas ao longo de 2010 e 2011 nas residências dos informantes e caracterizaram-se como semiestruturadas e individuais.

A opção pelo município de Lajeado como área de abrangência da pesquisa foi feita devido à existência da coleta seletiva instalada desde 1994 e pela acessibilidade aos dados. O município localiza-se no Vale do Taquari, região central do Rio Grande do Sul, a 120 km de Porto Alegre, capital do Estado. A economia do município é baseada nas grandes indústrias alimentícias, seguidas do comércio e setor de serviços. O município é considerado pólo econômico e urbano da região, que tem cerca de 350.000 habitantes. A população de Lajeado é formada basicamente por descendentes de imigrantes alemães, italianos, africanos e portugueses que totalizam 78 mil habitantes (IBGE, 2015). 


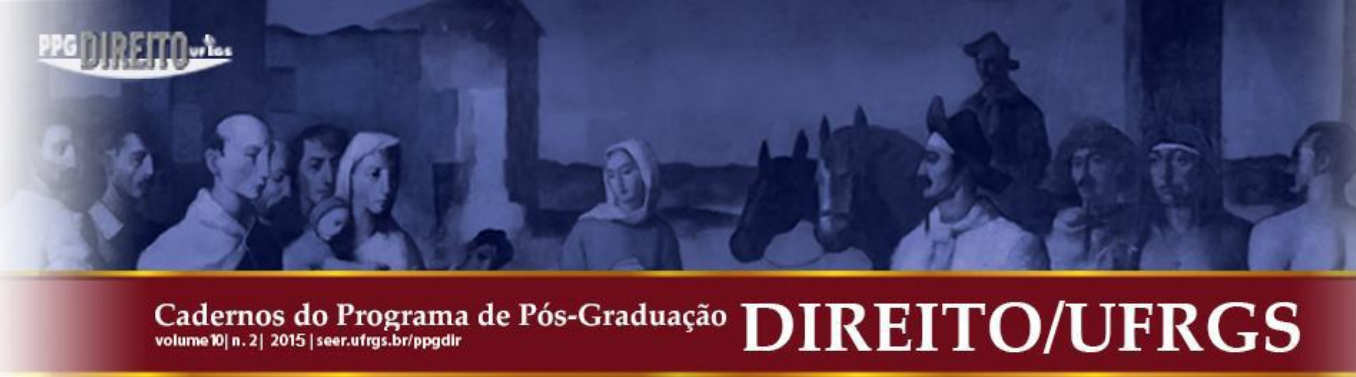

\subsection{Tratamento dos dados}

As entrevistas gravadas foram transcritas e interpretadas através da análise de conteúdo qualitativa, levando-se em conta as ideias centrais dos entrevistados sobre o tema da pesquisa. Houve uma leitura integral e detalhada das informações coletadas em cada entrevista, a fim de compreender as representações sobre a responsabilidade na destinação dos resíduos sólidos domésticos. Em seguida, foi realizada uma releitura para identificar os significados comuns para definições de grupos de respostas para cada categoria de análise. Conforme Bardin (1977, p. 117), as categorias são "rubricas ou classes, as quais reúnem um grupo de elementos sob um título genérico, agrupamento esse efetuado em razão de caracteres comuns desses elementos".

\section{APRESENTAÇÃO DOS RESULTADOS DA PESQUISA}

Neste capítulo são tratados os resultados das entrevistas aplicadas aos 120 moradores de Lajeado sobre três categorias: a) responsabilidade sobre os resíduos sólidos, b) informação, c) modos de interação envolvidos. Os dados coletados por meio das entrevistas semiestruturadas foram agrupados por proximidade de respostas e indicam modos de representar a problemática dos resíduos no município.

a) Responsabilidade sobre os resíduos sólidos

Acerca da categoria responsabilidade, quando perguntados se os entrevistados separavam o lixo - o uso da palavra "lixo" ao invés de "resíduos" se deve à opção pelo termo mais popular entre os moradores -, observaram-se quatro grupos de respostas: os que faziam a separação básica entre seco e úmido; os que realizavam a separação básica, com uma separação mais especializada dos resíduos secos; os que realizavam uma separação parcial e, ainda, os que não realizavam.

O grupo que fazia a separação básica considerava esta uma prática fácil. O grupo que efetuava a separação especializada era motivado pela possibilidade de guardar metal, vidro e papelão para reuso. Outro grupo de entrevistados declarou dispor os materiais em sacolas separadas em resíduos da cozinha, do banheiro e o seco. Há também o grupo dos que armazenavam os resíduos em sacolas ou locais diferentes, para que os lixeiros ou catadores 


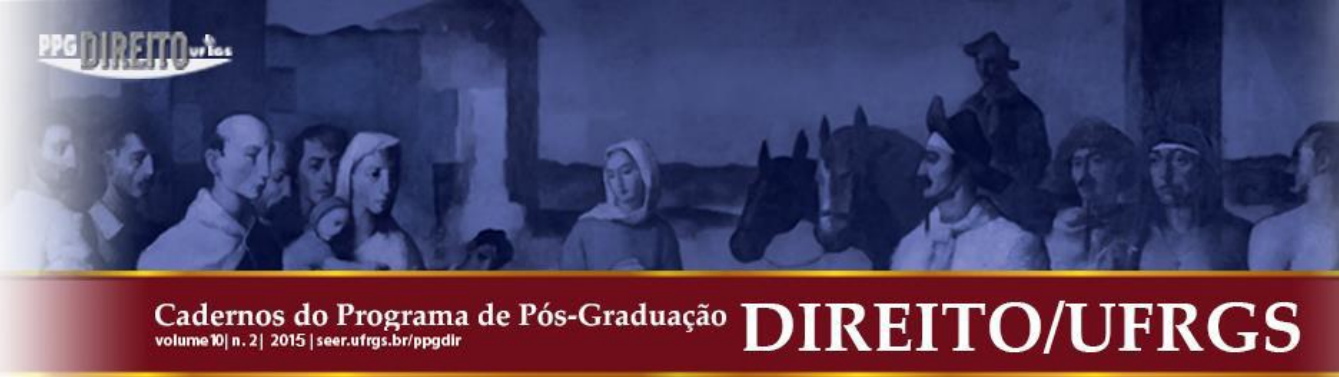

percebessem a diferença entre os tipos de resíduo. Nas entrevistas emergiram respostas referindo-se à coleta como um processo ineficiente, por que mesmo separando o morador percebia que a empresa responsável pela coleta realizava o recolhimento por meio de um único veículo, reunindo todos os resíduos. Outro entrevistado declarou que todos na casa eram parentes e, portanto, separavam juntos, destinando alguns resíduos secos para o aproveitamento pelas crianças da família. Há cidadãos que afirmaram transferir a responsabilidade da segregação para uma pessoa específica na residência, geralmente a mãe ou a empregada.

Há o grupo dos que não separavam, assim como os que realizavam a separação parcial, pois mencionaram separar apenas alguns itens, como as garrafas pet. Portanto, os resíduos não eram triados frequentemente ou adequadamente.

Questionados a respeito de quem é a responsabilidade sobre o lixo e se o cidadão acha que tem alguma responsabilidade sobre sua separação, obteve-se dois grupos de respostas: o grupo dos entrevistados que assumiu a responsabilidade e o grupo de entrevistados que transferiu a responsabilidade para o poder público. No primeiro observou-se que os cidadãos assumiram como um dever a sua responsabilidade sobre a correta segregação e destinação do lixo. Já no segundo grupo os entrevistados responderam que todos possuíam responsabilidade sobre o lixo, porém o governo, o estado e o município possuíam mais obrigações. As falas em sua grande maioria mencionaram a prefeitura como a responsável pelo lixo, especialmente o setor de meio ambiente. Há cidadãos que justificaram suas respostas declarando que o lixo era posto em via pública e que pagavam impostos e taxas para que este fosse recolhido, considerando assim que a responsabilidade, após a disposição, seria do poder público. Nas respostas evidenciou-se que há moradores que não se informavam sobre o tema.

\section{b) Informação}

Quanto à categoria informação, questionados sobre o que é feito com o lixo depois de recolhido na lixeira, surgiram dois conjuntos de respostas: aqueles com informação parcial e aqueles sem informação do que era feito com os resíduos.

Os entrevistados que possuíam informação parcial referiram que o lixo recolhido era encaminhado para o aterro sanitário, ou para o "lixão" ou, ainda, que este era reciclado. O local da reciclagem não se mostrou conhecido por eles. Há moradores que foram informados em palestras sobre o lugar onde o lixo era colocado: o lixo orgânico iria para o aterro e o seco 


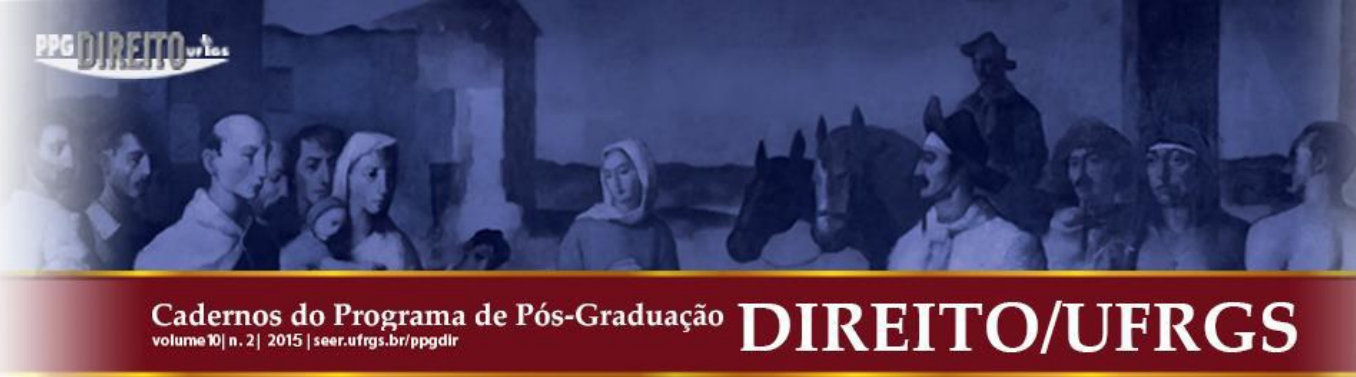

não souberam informar. Os moradores demonstraram desconhecimento com o que ocorre com o lixo depois de recolhido, apesar de terem informação parcial sobre o tema. Há de se salientar que no município, todos os resíduos seguem para o aterro sanitário.

Indagados a respeito de quem são as pessoas envolvidas na questão dos resíduos sólidos, um grupo de entrevistados referiu não saber quem são as pessoas envolvidas ou não ter interesse na questão. O grupo que identificou os envolvidos citou a prefeitura, a Secretaria do Meio Ambiente, a Secretaria Municipal do Planejamento, a Secretaria Municipal de Saneamento, a Fundação Estadual de Proteção Ambiental - FEPAM, o Centro Universitário Univates, a mídia, os professores, as crianças e o povo. A maioria dos entrevistados mencionou a prefeitura como responsável por tudo que diz respeito aos resíduos sólidos domésticos.

Quando questionados sobre onde e como buscam informação acerca das questões ambientais uma minoria dos entrevistados declarou interesse neste tipo de informação. Uma grande parte dos entrevistados declarou que não se interessava pelo assunto. Aqueles que demonstraram ter interesse informaram que assistiam notícias e programas ecológicos na televisão; escutavam rádio; procuravam por reportagens em jornais, revistas, internet; liam panfletos distribuídos nas ruas; já ter feito algum curso ambiental; ou discutiam o tema em reuniões de amigos.

Verificou-se, ainda, que um grupo de entrevistados recebia informação ambiental em situações determinadas ou pontuais, como em palestras no bairro, clube de mães ou conversas com agentes de saúde, na escola por terem filhos em idade estudantil, por serem alunos ou professores, em palestras educativas no trabalho e por meio de programas de educação ambiental da prefeitura.

Quando perguntados se os meios de comunicação abordam as questões ambientais e questões sobre o lixo, a maioria concordou, mas houve quem não sabia informar. Entre os meios de comunicação que abordam a questão foram identificados, principalmente, a televisão e o rádio, apesar de considerarem que abordam pouco esses assuntos, podendo haver maior divulgação.

c) Modos de interação envolvidos

Quanto aos modos de interação social envolvidos na questão dos resíduos buscou-se identificar se os moradores percebem que há preocupação com o lixo doméstico. Um grupo de 


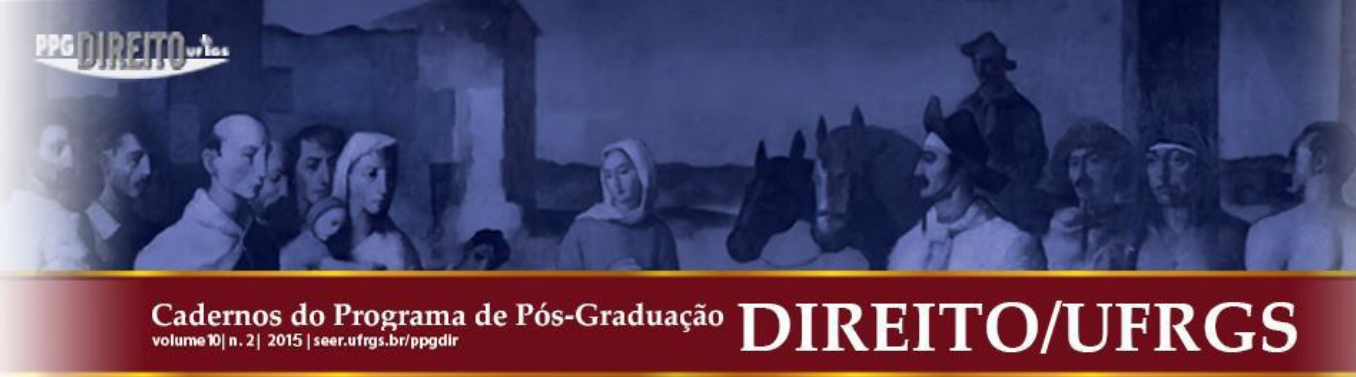

respondentes identificou que as pessoas estariam começando a se conscientizar pelo fato de escutarem notícias no rádio e na televisão relacionados ao tema. Mencionaram haver pessoas que não separam o lixo, mas colocam os resíduos nas lixeiras evitando os locais indevidos, como terrenos baldios.

Os discursos, na grande maioria, demonstraram que há uma preocupação dos entrevistados, no entanto não percebiam como uma prática de todos os munícipes. Isso porque observaram que grande parte da população mistura os resíduos.

Houve menção ao excesso de embalagens dos produtos que, quando descartadas, aumentam o volume de resíduos. Alguns respondentes referiram-se, ainda, ao consumo exagerado e a pessoas que queimam os resíduos. Demonstraram perceber que falta esclarecimento, já que sua geração não teve informação ambiental. Um grupo de entrevistados demostrou não perceber a prática do reaproveitamento dos materiais.

A última pergunta da entrevista buscou identificar se os moradores participavam de algum grupo social que tratasse de questões ambientais. Grande parte dos entrevistados disse não participar de nenhum grupo social. Dos entrevistados que participavam, a maioria afirmou haver troca de informações sobre questões ambientais nos encontros de clube de mães, igreja, associação de moradores, roda de amigos, turma de bolão, grupo de terceira idade, reuniões do posto de saúde, Espaço Vida da Unimed, Clube Lions e encontros com os funcionários da Emater. Uma pequena parte dos entrevistados que participava de algum grupo social referiu que as questões ambientais não eram tema das reuniões.

\section{DISCUSSÃO DOS RESULTADOS}

A pesquisa empírica expõe a sucessão de deveres não cumpridos - do Estado de informar, do cidadão de informar-se sobre as questões dos resíduos, do cidadão de zelar pelo ambiente equilibrado - o que infringe a Constituição Federal, a Política Nacional de Meio Ambiente e a Política Nacional de Resíduos Sólidos. Quando não se cumprem estes deveres caberia aos seus responsáveis responder pelos danos decorrentes de seus atos. Mas como identificar e qualificar os danos decorrentes do dever não cumprido de se buscar informação ambiental? A sociedade precisa avançar nesta discussão, de modo a ocupar este vazio legal.

A ética utilitarista que permeia as práticas de descarte dos resíduos feita pelos cidadãos e pelos produtores de bens de consumo sofre um revés considerável com a Política 


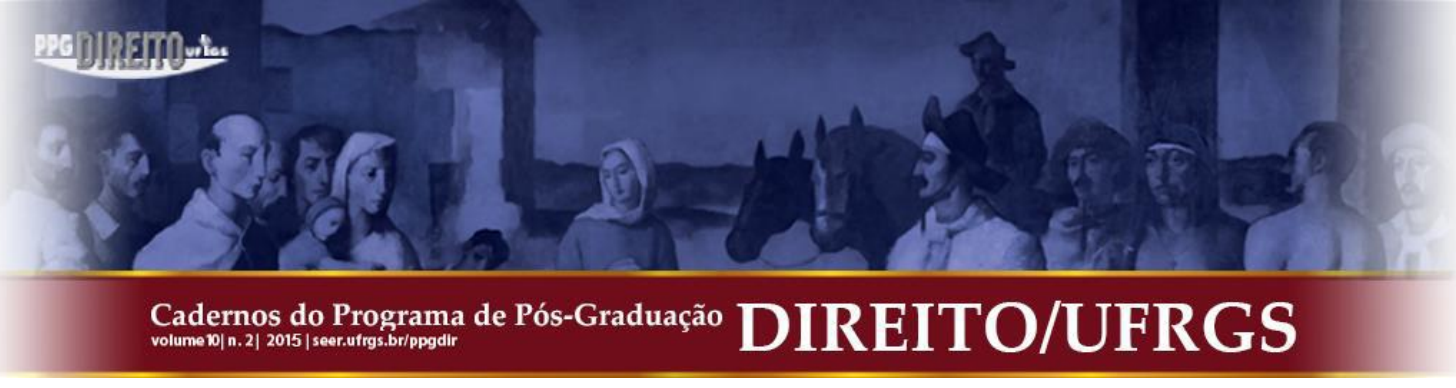

Nacional de Resíduos Sólidos, na qual o meio ambiente é colocado na sua condição de fragilidade impondo-se, como defende Zancanaro (2003), a responsabilidade jurídica às decisões tomadas no processo de consumo e descarte. Cidadãos, Estado e produtores de bens de consumo são chamados a refletir sobre seus fazeres, a adotarem condutas de cautela e posturas moderadas a partir do pensar hipotético e sobre as conseqüências de seus atos, como Noal (2008) propõe.

No entanto, é preciso motivar a mudança social, o desejo dos geradores de resíduos de assumirem a responsabilidade pelo cuidado ambiental. Coloca-se, assim, a necessidade de utilização de estratégias de comunicação que informem e sensibilizem os diferentes atores geradores de resíduos para práticas legais e éticas relacionadas ao exercício da cidadania ambiental. Sem informação não é possível o pensar reflexivo, que é determinante para a livre escolha e para a participação social. Assim como a informação, a participação refere-se a um direito-dever, fundamental da constituição da cidadania ambiental. Esta, para se fazer realidade na sociedade contemporânea, requer uma transformação no jeito de pensar e viver, direcionando-se a uma ética solidária e fraterna com todas as formas de vida.

A tendência dos moradores é ainda de transferência da responsabilidade no trato com seus resíduos para o poder público, o que remete a um distanciamento em relação aos aspectos éticos apresentados pelos autores. No entanto já se observa a tendência à segregação dos resíduos como uma prática mais comum a cada dia, o que remete às transformações do viver que surgem a partir da implantação da política de coleta seletiva municipal. Muitos moradores já entendem que a responsabilidade é compartilhada entre pelo menos o cidadão e o poder público, confluindo estas percepções com o disposto na lei.

Quanto à busca de informação pelos moradores sobre como agir com os resíduos, esta ainda é tida como bastante tímida, reduzindo-se à informação que lhes chega pelos meios de comunicação de maior acesso - rádio e canais de televisão aberta - os quais não construíram ainda uma cultura de oferta de informação ambiental como um aspecto educativo. Os moradores desconhecem o destino dos seus resíduos após serem descartados. A falta destas informações pode estar determinando a falta de responsabilização, desinteresse e não participação na política de coleta seletiva. Há uma confusão, inclusive, sobre quem é o agente responsável pela coleta, um serviço que os moradores reconhecem como pago anualmente na taxa do Imposto Predial Territorial Urbano (IPTU). O desconhecimento do destino dos seus 


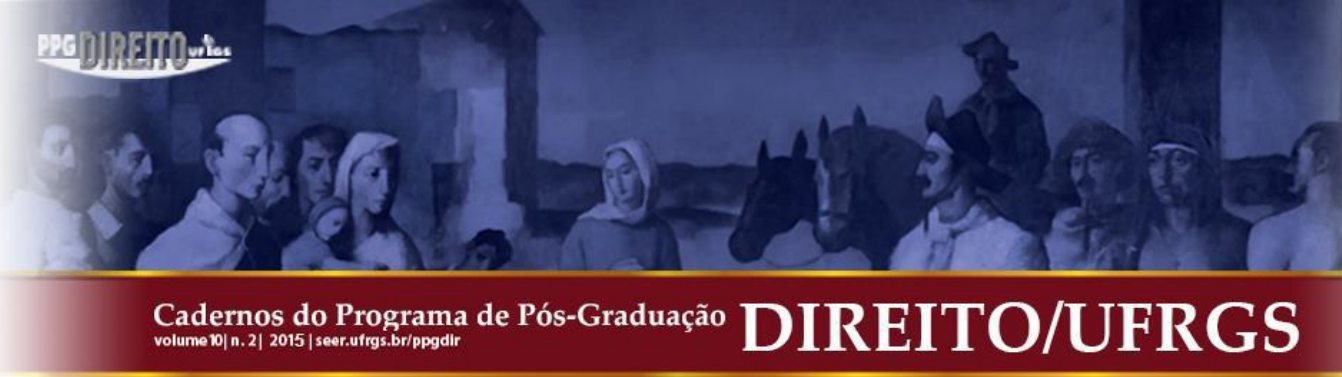

resíduos após descartá-los na lixeira afronta o disposto no atual contexto legal, visto que é dever do cidadão a proteção ao meio ambiente o que inclui a busca da informação.

Cada cidadão possui direitos que estão garantidos em lei, como por exemplo, ter um ambiente limpo, adequado para as condições humanas, mas em contrapartida, aos mesmos também são atribuídos deveres, que estão positivados em leis, o que significa colaborar com esse ambiente, dispor os resíduos adequadamente, buscar informação ou exigir dos órgãos responsáveis informação e educação ambiental.

Sem informação ambiental o cidadão não reconhece seus direitos e deveres. O direito à informação ambiental, positivado constitucionalmente, também é um pressuposto importante para que a participação popular seja efetiva na proteção do meio ambiente.

Os moradores não percebem uma preocupação coletiva com a questão dos resíduos na comunidade em que vivem, o que reflete as posturas individuais dos entrevistados. Do mesmo modo, a não participação na política de coleta seletiva parece refletir a pouca participação em outros contextos de interação social, o que se explicitou na fala dos informantes.

O problema dos resíduos é um problema contemporâneo, decorrente do crescimento demográfico, dos avanços tecnológicos e da oferta de produtos para o consumo imediato, com obsolescência planejada, o que conjuga-se com o despreparo dos gestores públicos pra enfrentar as complexidades decorrentes deste cenário.

Trata-se de um fator de risco ambiental, que afeta a saúde e a vida pensada ecossistemicamente. A prática cotidiana, trivial, de descartar resíduos não é percebida de forma encadeada a vida. Não há uma reflexão sobre a proveniência dos materiais que compõem o que se consome e tampouco das consequências do descarte inadequado, mesmo havendo legislação sobre acesso à informação, sobre meio ambiente e, especificamente, sobre resíduos. A lei está ainda distante das práticas cotidianas, tem pouco poder transformativo para o pensar e o agir em relação aos resíduos sólidos domésticos. Isto se comprova na informação, da Secretaria de Meio Ambiente de Lajeado, de que em 2015 apenas 3\% das 70 toneladas diárias de resíduos coletados serviam para a reciclagem (por se enquadrarem como seco), quando $30 \%$ seria passível de gerar novos produtos. Portanto, recicla-se apenas $10 \%$ do que é potencialmente reciclável.

O estudo realizado indica que a postura cidadã ambiental está no horizonte no que se refere a uma preocupação ética com a dignidade, à qualidade de vida, ao ambiente percebido como patrimônio comum da humanidade, ao desenvolvimento humano (em lugar do 


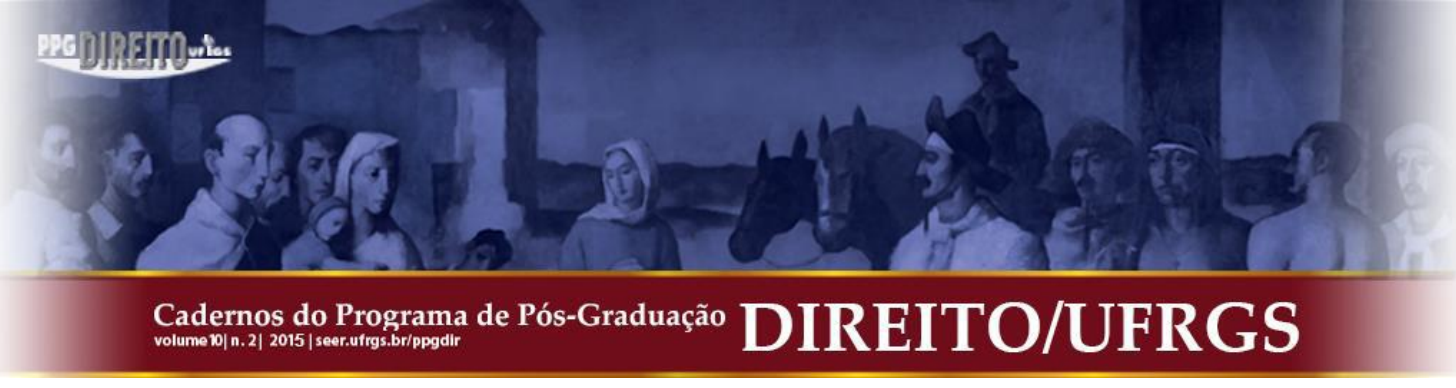

crescimento mensurável pelo Produto Interno Bruto - PIB), ao controle social, à proteção intercomunitária, à busca e recebimento de informação ambiental, enfim ao dever moral de não prejudicar outrem, entendido como humano ou natureza.

Portanto, valida-se a teoria de Boaventura Sousa Santos quando refere que o equilíbrio pretendido entre regulação e emancipação não foi conseguido: “Á medida que a trajetória da modernidade se identificou com a trajetória do capitalismo, o pilar da regulação veio a fortalecer-se à custa do pilar da emancipação" (SANTOS, 2001, p. 236). ' Segundo o autor, o pilar da regulação é formado por Estado, mercado e comunidade, sendo que a hipertrofia do mercado se deu em detrimento do Estado e de ambos em detrimento da comunidade. $\mathrm{O}$ autor identifica uma colonização do Estado pelo mercado. Exemplo disso se observa quando o consumo é assumido pelo Estado brasileiro praticamente como parte de uma política econômica baseada no crescimento e não no desenvolvimento.

Quanto à comunidade, Santos entende que o desenvolvimento da subjetividade atomizada - dos cidadãos autônomos e livres, individualizados, portanto uma proposta hegemônica liberal - suplantou a subjetividade coletiva articulada com o sentido de comunidade, e com isso a obrigação política cidadão-cidadão na qual se baseia a política participativa (originária no contrato social de Rosseau), que hoje é mais formal que substantiva. Para o autor, "subjectividade sem cidadania conduz ao narcisismo e ao autismo" (SANTOS, 2001, p. 256). A cidadania se empobrece na sociedade liberal por ser mais burocrática e reguladora que emancipatória. Isto traz consequências ambientais, tornando utópica a utopia ecológica, denominada por Santos,

\begin{abstract}
"porque sua realização pressupõe a transformação global, não só dos modos de produção, mas também do conhecimento científico, dos quadros de vida, das formas de sociabilidade e dos universos simbólicos e pressupõe acima de tudo uma nova relação paradigmática com a natureza, que substitua a relação paradigmática moderna. É uma utopia democrática porque a transformação a que aspira pressupõe a repolitização da realidade e o exercício radical da cidadania individual e colectiva, incluindo nela a carta dos direitos humanos da natureza. É uma utopia caótica porque não tem um sujeito histórico privilegiado. Os seus protagonistas são todos os que, nas diferentes constelações de poder que constituem as práticas sociais, têm consciência de que a sua vida é mais condicionada pelo poder que outros exercem sobre eles do que pelo poder que exercem sobre outrem" (SANTOS, 2001, p. 44)
\end{abstract}

\footnotetext{
$\dagger$ “O pilar da emancipação é constituído pela articulação entre três dimensões da racionalização e secularização da vida colectiva: a racionalidade moral-prática do direito moderno; a racionalidade cognitivo-experimental da ciência e da técnica modernas; e a racionalidade estético-expressiva das artes e da literatura modernas. $\mathrm{O}$ equilíbrio pretendido entre a regulação e a emancipação obtém-se pelo desenvolvimento harmonioso de cada um dos pilares e das relações dinâmicas entre eles." (SANTOS, 2001, p. 236).
} 


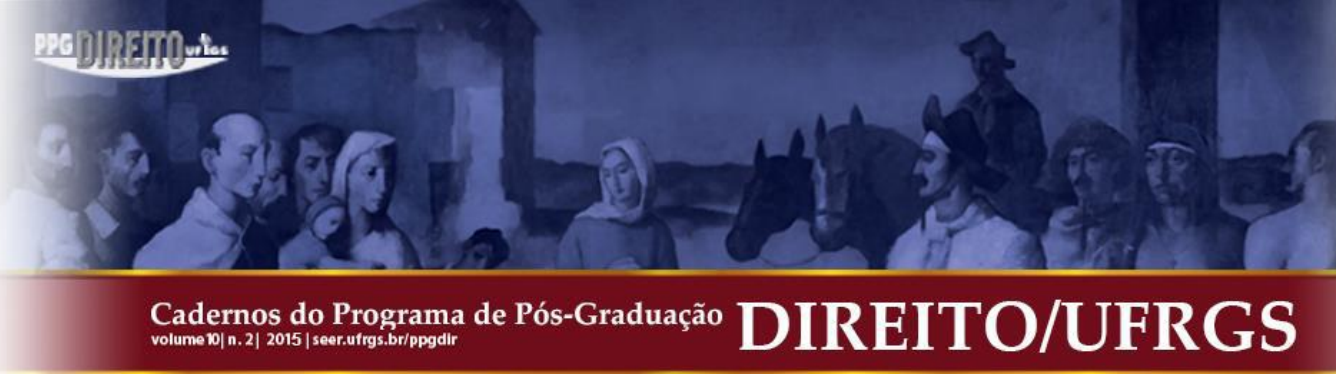

Por fim, o autor indica o cotidiano como o lugar do protagonismo pessoal e grupal necessário para se fundar uma nova relação entre subjetividade e cidadania, incentivadora da autonomia, das competências interpessoais e coletivas. Portanto, fundadoras de novas relações entre cidadãos e Estado e destes com o mercado, de modo a diminuir o desequilíbrio entre regulação e emancipação. Práticas que, no caso do nosso objeto de estudo, começam nos fazeres domésticos. Assim, o pessoal é político, como infere Giddens (2002), que entende ser a política da vida uma dimensão complementar da política emancipatória e vice-versa.

\section{CONSIDERAÇÕES FINAIS}

Tem-se, ao cabo das análises realizadas a compreensão que, tratando-se das responsabilidades quanto à disposição dos resíduos, cabe ao poder público, setor empresarial e coletividade a efetividade das ações voltadas para assegurar a Política Nacional de Resíduos Sólidos. As pessoas físicas ou jurídicas são responsáveis pela implementação e operacionalização integral do plano de gerenciamento de resíduos sólidos. O gerador de resíduos sólidos domésticos é responsável pela sua disponibilização adequada para coleta, assim como pelo pensar sobre a possibilidade de não geração.

A Política Nacional de Resíduos Sólidos relaciona informação-participaçãoresponsabilidade compartilhada como pressuposto para ação dos diferentes geradores de resíduos, de modo a se evitar danos ambientais e, deste modo, direciona a sociedade brasileira para um agir ético que inclui a percepção da interdependência entre os diferentes atores da sociedade e entre esta e o ambiente.

Apoiar o aumento do consumo, prática adotada pelos governantes brasileiros em busca de crescimento econômico, tem como consequência a maior produção de resíduos e acarreta riscos ambientais quando não há a destinação adequada dos resíduos (a falta de aterros sanitários é flagrante ainda em grande parte dos municípios do Brasil). Estes riscos são assumidos conjuntamente por quem se engaja na lógica do consumo (Estado, produtores de bens e cidadãos), que assim não cumprem seu dever de zelar pela minimização de impactos ao ambiente, o que muitas vezes decorre da falta de informação ambiental. 


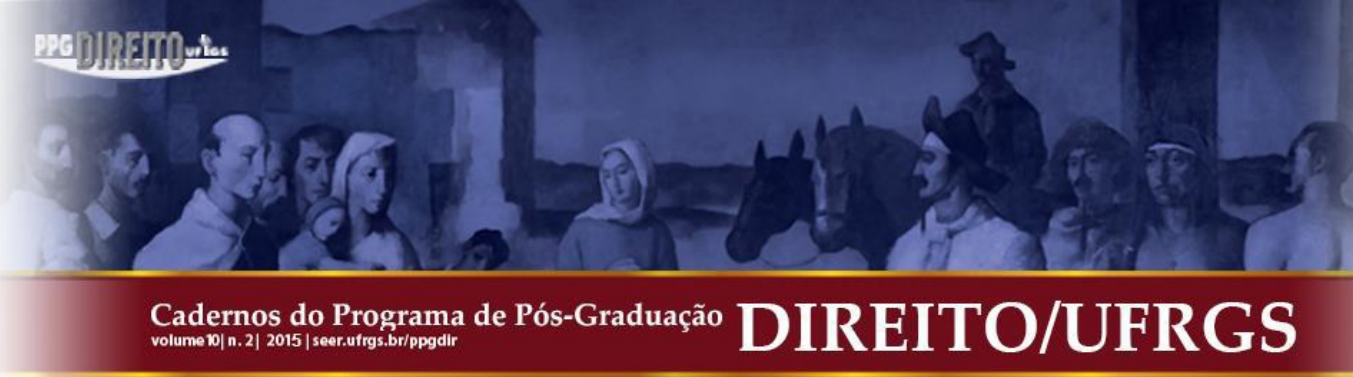

A Política Nacional dos Resíduos Sólidos avança ao propor a responsabilidade compartilhada, incluindo o cidadão-indivíduo como um dos atores responsáveis, assim como os poderes públicos e as indústrias produtoras de bens de consumo.

No entanto, as representações expostas nas falas dos moradores entrevistados apontam que o direito ao ambiente equilibrado não se concretiza muitas vezes pelo dever não assumido de evitar o consumo excessivo e de dispor adequadamente os resíduos, o que interfere diretamente na sua qualidade de vida e na da comunidade, afetando o respeito a direitos fundamentais.

Por parte do município, cabe à busca do engajamento e participação da população na política de coleta seletiva, sob pena de se seguir infringindo a Política Nacional de Resíduos Sólidos. Além das providências legais e as implicações éticas e morais devem permear o cotidiano das políticas públicas relacionadas aos resíduos.

\section{REFERÊNCIAS}

BARDIN, Laurence. Análise de Conteúdo. Portugal: Presses Universitaires de France, 1977.

BOFF, Leonardo. Ética e moral: a busca dos fundamentos. Rio de Janeiro: Vozes, 2003.

BONAVIDES, Paulo. Curso de Direito Constitucional. 12. ed. São Paulo: Malheiros, 2002.

BRASIL. Constituição da República Federativa do Brasil de 1988. 42. ed. São Paulo: Saraiva.

BRASIL. Lei $n^{\circ}$ 6.938, de 31 de agosto de 1981. Política Nacional do Meio Ambiente. Disponível em: http://www.planalto.gov.br/ccivil/Leis/L6938org.htm. Acesso em: junho de 2009.

BRASIL. Resolução 196, de 10 de outubro de 1996. Conselho Nacional de Saúde. Disponível em: http://conselho.saude.gov.br/comissao/conep/resolucao.html. Acesso em: junho de 2009.

BRASIL. IBGE. http://www.ibge.gov.br.Acesso em: setembro de 2015. 


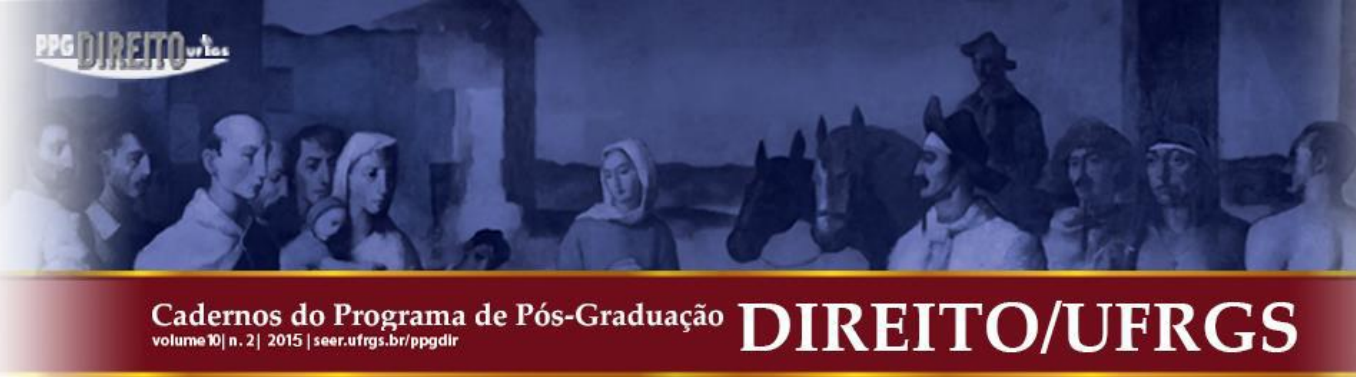

BRASIL. Resolução CONAMA $N^{o}$ 005, de 05 de agosto de 1993. Disponível em: http://www.lei.adv.br/005-93.htm. Acesso em: maio de 2009.

BRASIL. Lei $n^{\circ} 12.305$, de 02 de agosto de 2010. Política Nacional de Resíduos Sólidos. Disponível em: http://www.camara.gov.br/sileg/integras/501911.pdf. Acesso em: setembro de 2010.

BREVIDELLI, Maria Meimei; DE DOMENICO, Edvano Birelo Lopes. Trabalho de Conclusão de Curso: guia prático para docentes e alunos.1 ed. São Paulo: Látria, 2006.

DALlARI, Dalmo. Direito de participação. In: SPOSATI, Aldaísa et. al. (org.). Ambientalismo e participação na contemporaneidade. São Paulo: FAPESP, 2002.

DECLARAÇÃO de Estocolmo sobre o Ambiente Humano. Declaração da Conferência das Nações Unidas sobre o Meio Ambiente Humano, 1972. Estocolmo. Disponível em http://www.vitaecivilis.org.br/anexos/Declaracao_Estocolmo_1972.pdf. Acesso em 12 de julho de 2011.

GENTILLI, Davi Lopes. Direito à informação e direito à comunicação: o percurso do jornalismo na constituição da cidadania. INTERCOM. XXXV Congresso Brasileiro de Ciências da Comunicação. Fortaleza, CE - 3 a 7/9/2012.

GIDDENS, Anthony. Modernidade e identidade. Rio de Janeiro: Zahar, 2002.

JONAS, Hans. O principio responsabilidade: ensaio de uma ética para a civilização tecnológica. Rio de Janeiro: Editora PUC - Rio, 2006.

JUNGES, José Roque. Ética ambiental. São Leopoldo: UNISINOS, 2004.

LEITE, José Rubens Morato. AYALA, Patryck de Araújo. Direito Ambiental na Sociedade de Risco. Rio de Janeiro: Forense Universitária, 2004.

LEITE, José Rubens; CANOTILHO, José Joaquim Gomes. Direito Constitucional Ambiental Brasileiro. São Paulo: Saraiva, 2007.

MILARÉ, Édis. Direito do Ambiente. São Paulo: RT, 2000. 
